\title{
DE ADJUVANTE A PROTAGONISTA: A CONSTRUÇÃO DA IMAGEM DO NEGRO NA PUBLICIDADE BRASILEIRA
}

\author{
Luciana Carmona Garcia Manzano ${ }^{1}$ \\ Isaac D'Leon de Almeida ${ }^{2}$
}

\begin{abstract}
Resumo
A formação social brasileira é resultado de um modelo que se constitui pela mistura de etnias que fizeram do Brasil um mosaico de diversidades, portador de riquezas multivariadas. Embora tenha sido constituído de forma pluralizada, isso não evitou a discriminação. Dentro dessa temática, este artigo objetiva analisar a imagem do corpo negro em peças publicitárias brasileiras que circularam no período de 1995 a 2016, no intuito de observar a correlação do discurso presente com os indícios que remetem à subjetivação do negro num patamar inferior ao do branco. À luz da teoria da Análise do Discurso, buscamos observar a construção da imagem do negro nas práticas discursivas ao longo da história. Os resultados demonstram a presença desses indícios do negro inferiorizado, reatualizado no discurso da publicidade, mas, a partir das políticas afirmativas, observamos uma tentativa de mutações na construção desses discursos e a busca de uma representatividade do negro na publicidade contemporânea.
\end{abstract}

Palavras-chave: Análise do Discurso. Discurso publicitário. Corpo negro.

\section{FROM ADJUVANT TO PROTAGONIST: THE CONSTRUCTION OF THE BLACK PEOPLE'S IMAGE IN THE BRAZILIAN PUBLICITY}

\begin{abstract}
The Brazilian social formation is the result of a model that is constituted by the mixture of ethnic groups that has made of Brazil a mosaic of diversities and multivariate riches. Although it was created in a pluralized way, this did not avoid the discrimination. Within this theme, the objective of this article is to analyze the image of the black people in Brazilian advertising pieces that circulated in the period from 1995 to 2016, in order to observe the correlation of the present discourse with the indications that refer to the subjectivation of the black people at a lower level than white people. Based on the Discourse Analysis theory, our analyses seeks to observe the construction of the image of the black people in discursive practices throughout history. The results demonstrated the presence of these indices of an inferiorized black people and re-update by the publicity discourse. However, from the affirmative policies, we observe changes in the construction of these discourses and the black people begins to conquer, gradually, its representativity in the contemporary publicity.
\end{abstract}

Keywords: Discourse Analysis. Black person. Advertising Discourse.

\section{INTRODUÇÃO}

\footnotetext{
${ }^{1}$ Universidade de Franca, Franca (UNIFRAN) - São Paulo - Brasil. Doutora em Linguística pela Universidade Federal de São Carlos (UFSCar). Docente do Programa de Pós-Graduação em Linguística da Universidade de Franca. ORCID <https://orcid.org/0000-0002-5280-4444>. E-mail: lcgmanzano@gmail.com.

${ }^{2}$ Centro Universitário de Formiga (UNIFOR-MG), Formiga - Minas Gerais - Brasil. Mestrado em Linguística pela Universidade de Franca. Professor do Centro Universitário de Formiga nos cursos de Administração, Arquitetura e Urbanismo e Curso Superior de Tecnologia em Marketing. E-mail: isaacdleon@hotmail.com.
} 


\section{Linguagens - Revista de Letras, Artes e Comunicação - ISSN 1981- 9943 \\ Blumenau, v. 14, n. 3, p. 267-285, set./dez. 2020. \\ DOI: http://dx.doi.org/10.7867/1981-9943.2020v14n3p267-284}

Ao longo da história brasileira, circulam discursos que nos marcam como sujeitos de uma nação formada por meio da mistura de etnias. A partir dessa ideia de fusão étnica, observam-se discursos que remontam, não raro, à colonização do Brasil, trazendo à tona marcas e resquícios de um período que continua fazendo eco na atualidade e que (re)produz a marginalização dos corpos dos excluídos.

Compreender as condições de emergência e de circulação dos discursos é imprescindível para trazer à tona as questões que evidenciam a permanência de determinados sentidos. Para isso, é necessário compreender como são construídos os sentidos ao longo da história e como as relações de poder se dão de modo a reiterar discursos dominantes e dominados.

Esta reflexão que, agora, baseia este artigo, surgiu da observação de enunciados cotidianos que colocavam em xeque a existência de preconceito racial no país. O discurso que insiste em eclodir é o de que o Brasil é um país miscigenado, logo, não há espaço para discriminações raciais. No entanto, a investigação da irrupção dos discursos, ao menos no campo publicitário, como pretendemos analisar, aponta para a circulação de sentidos que remetem à escravidão e ao período que se seguiu a ela: o negro, desde que fora liberto, passou a representar perigo à hierarquização já bem consolidada da sociedade branca brasileira; deixálo à margem era necessário para a manutenção de uma ordem política e social. Assim,

\footnotetext{
As representações construídas sobre o corpo negro refletem os dramas da hierarquização social após o dia 13 de maio de 1888, data que inaugurou um momento da vida brasileira em que seus cidadãos passaram a ser equiparados dos pontos de vista jurídico e social. Depreende-se daí uma das estratégias utilizadas para a reprodução "informal" dos preconceitos, uma das principais características do "racismo à brasileira. (ABRAHÃO; SOARES, 2011, p. 277-278).
}

Desse modo, sob o falso signo da "miscigenada" população brasileira, progressivamente, houve o apagamento da identidade negra, invisibilizada em função de uma identidade nacional. "Uma série de símbolos vão virando mestiços, assim como uma alentada convivência cultural miscigenada se torna modelo de igualdade racial" (SCHWARCZ, 2012, p. 68).

Nessa linha de raciocínio, nosso questionamento é: os discursos colocados em circulação no campo da publicidade brasileira no século XXI ainda trazem ecos do período escravocrata? De que modo se dá esse funcionamento? Existe um reflexo das políticas afirmativas na publicidade brasileira contemporânea? 


\section{Linguagens - Revista de Letras, Artes e Comunicação - ISSN 1981- 9943 \\ Blumenau, v. 14, n. 3, p. 267-285, set./dez. 2020. \\ DOI: http://dx.doi.org/10.7867/1981-9943.2020v14n3p267-284}

Para tanto, e por conta das limitações do gênero textual artigo, trazemos como amostragem de análise três peças publicitárias brasileiras que circularam no período de 1995 a 2016, no intuito de observar a correlação do discurso presente com o que chamaremos de marcas da senzala, trazida como expressão linguística, neste artigo, a partir de uma relação simbólica com os indícios que remetem à subjetivação do negro num patamar inferior ao do branco $^{3}$.

Nosso embasamento teórico se faz à luz de reflexões discursivas de autores como Michel Foucault ([1969] 2014) e Jean-Jacques Courtine (2009) no que concerne à noção de memória discursiva, que postula que todo dizer é atravessado por outros dizeres e, em consequência, produz efeitos de memória específicos: lembrança, esquecimento, reiteração ou apagamento de sentidos. Frente à própria inscrição histórica do enunciado, ele se torna sempre outro, coloca-se em um campo de memória e, na relação com outros enunciados em um domínio de coexistência, está aberto à repetição, à transformação, à (re)atualização.

Por meio da observação da inserção do corpo negro nas campanhas publicitárias ao longo das últimas décadas, nossa análise se desenvolve no intuito de estudar os efeitos de sentido e de memória que inscrevem o negro historicamente na sociedade. Assim, busca-se observar como o funcionamento do discurso publicitário, a partir da inserção do negro em suas peças, se modificou ao longo dos anos, fomentado pelos movimentos sociais e pelas políticas afirmativas.

O método arqueológico desenvolvido por Foucault ([1969] 2014) possibilita associar o sujeito e o enunciado, proporcionando um olhar analítico capaz de desmontar os discursos presentes nas peças publicitárias trabalhadas na pesquisa em partes menores e, principalmente, contextualizadas por sua historicidade, permitindo uma leitura que incita o analista a "escavar" os indícios responsáveis por sua construção discursiva.

A materialidade das peças publicitárias analisadas se constitui de enunciados sincréticos, que articulam verbo e imagem, movimento e expressão gestual. É possível verificar que as peças trabalham a fusão de linguagem verbal e visual, têm como ponto convergente a presença de uma figura negra.

\footnotetext{
${ }^{3}$ Estas análises têm como base os resultados e reflexões da dissertação intitulada "Marcas da senzala na construção da imagem do negro na publicidade brasileira contemporânea", de um dos autores deste artigo, a partir do qual os autores propõem um desenvolvimento progressivo, fruto de discussões posteriores à defesa do trabalho, realizada em 2016. O corpus da pesquisa em questão é composto por 15 peças publicitárias, que constituem uma série enunciativa, tendo como critério o fato de terem sido produzidas a partir da década de 90 , período que representa a fomentação das políticas afirmativas desenvolvidas no Brasil. Pela limitação de texto no gênero artigo, selecionamos três dessas peças para dar corpo à nossa reflexão.
} 


\section{Linguagens - Revista de Letras, Artes e Comunicação - ISSN 1981- 9943 \\ Blumenau, v. 14, n. 3, p. 267-285, set./dez. 2020. \\ DOI: http://dx.doi.org/10.7867/1981-9943.2020v14n3p267-284}

\section{DISCURSO, MEMÓRIA E O SUJEITO NEGRO NA HISTÓRIA}

A posição ocupada pelo sujeito varia conforme as relações de poder e saber. Gregolin (2007, p. 59) afirma que "é uma forma de poder que transforma os indivíduos em sujeitos". Por meio das relações de poder, os indivíduos são classificados em categorias que estabelecem uma política de verdade a partir da qual esses indivíduos se reconhecem e são reconhecidos.

Historicamente, os sentidos construídos em torno do (corpo do) sujeito negro, no Brasil, assentam-se em uma base escravocrata, que funda culturalmente a organização social, dado que a posição do negro escravizado frente a seu senhor branco e, por conseguinte, frente à população das demais classes econômicas é inferior (BRAGA, 2015). Essa marca na história da construção da nação fez com que os sentidos, ao circularem repetidamente nos enunciados, cristalizassem uma memória simbólica de adjetivação do negro, em uma cadeia de significantes que, continuamente, os dessubjetiva e os torna abjetos.

Assim, e de acordo com Schwarcz (2012, p. 32):

[...] estamos diante de um tipo particular de racismo, um racismo silencioso e que se esconde por trás de uma suposta garantia de universalidade e da igualdade das leis, e que lança para o terreno privado o jogo da discriminação. Em uma sociedade marcada historicamente pela desigualdade, pelo paternalismo das relações e pelo clientelismo, o racismo só se afirma na intimidade, não se afirma publicamente. No entanto, depende da esfera pública para a sua explicitação, numa complicada demonstração de etiqueta que mistura raça com educação e com posição social e econômica. (SCHWARCZ, 2012, p. 32).

Para Courtine (2009), a memória discursiva - que, no caso desta reflexão, rearticula sentidos de modo a reiterar a constituição histórica do sujeito negro na sociedade - se constitui um conceito analítico a partir da articulação entre dois modos de existência do discurso enquanto objeto de estudo: o primeiro deles se dá no nível da formulação material do discurso, a partir da qual se observa uma seleção léxico-visual (no caso do nosso objeto) que constrói o enunciado; o segundo, se dá no nível do enunciado, pois se inscreve enquanto instância de formação, repetição e transformação de elementos do saber em uma política de verdade, que regula as fronteiras sobre o que pode ou não ser dito em uma determinada conjuntura histórica. Desse modo, a memória discursiva se constrói como modo de observação do funcionamento dos discursos porque permite ao analista observar a articulação entre um já-dito antes, em outro lugar, com o dito que se busca analisar.

Dado que toda formulação se situa em um campo de outras formulações, presentes na (re)atualização dos enunciados, sempre no seio de uma dada condição histórica, a memória 


\section{Linguagens - Revista de Letras, Artes e Comunicação - ISSN 1981- 9943 \\ Blumenau, v. 14, n. 3, p. 267-285, set./dez. 2020. \\ DOI: http://dx.doi.org/10.7867/1981-9943.2020v14n3p267-284}

discursiva concerne à existência histórica do enunciado inserido em práticas discursivas reguladas socialmente, visando sobre distintos campos do saber, novos atos de linguagem que, em cujas formulações, seus dizeres são expressos e abertos a novas possibilidades de enunciação. A memória, vista pela historicidade do enunciado no interior de práticas discursivas, materializa-se por meio de diferentes funcionamentos discursivos ao fazer emergir subjetividades e sentidos, formando "uma rede em que discursos e dizeres dispersos produzem uma trajetória dos sentidos, que são sempre outros mediantes a descontinuidade histórica que os atesta" (FERNANDES, 2012, p. 96).

Calcada na existência histórica do enunciado, já que este, em suas margens, mantém formulações coexistentes as quais ele retoma, transforma, reformula e confronta, a memória discursiva faz ecoar em dada conjuntura ideológica condições de produção passadas que, retomadas e (re)significadas, promovem efeitos de sentidos outros.

Foucault (1995), ao falar sobre as relações de poder, observa que o poder não se instaura, senão se exerce sempre em relações, e analisa a atuação dos mecanismos de resistência nessa relação. Para ele, a resistência é a luta de forças travada entre sujeitos, que possibilita a construção da(s) subjetividade(s). Percebe-se, assim, que a tensão entre os poderes é responsável pela construção dos saberes que dão forma aos discursos e (re)produzem sentidos na atualidade. Essa tensão entre os poderes/resistências nos faz olhar para o objeto de estudo selecionado para compor este artigo e compreender que sua produção se dá ao longo de um processo sócio-histórico e político em que saberes caudatários de uma organização sociocultural colonialista se confrontam com novas vozes que se alçam na construção das políticas afirmativas do final do século XX.

\section{POLÍTICAS AFIRMATIVAS E O NEGRO NA MÍDIA}

As propostas de ação afirmativa no Brasil são recentes. Embora o racismo seja um fato na cultura e no tecido social brasileiro, os clamores desses movimentos ganharam voz e vez há pouco tempo. De acordo com Moehlecke (2002), o termo "ação afirmativa" originou-se nos EUA, em resposta aos movimentos populares que lutavam contra a segregação racial que imperava nos anos 60. Nesse cenário, nasceu a ideia de uma ação afirmativa que incumbe o Estado da obrigatoriedade de garantir que sejam elaboradas e que se façam cumprir leis antissegregacionistas. Além do cumprimento dessas leis, fica sob a responsabilidade do Estado o dever de assumir uma postura ativa que assegure melhores condições de vida para a população negra norte-americana. 


\section{Linguagens - Revista de Letras, Artes e Comunicação - ISSN 1981- 9943 \\ Blumenau, v. 14, n. 3, p. 267-285, set./dez. 2020. \\ DOI: http://dx.doi.org/10.7867/1981-9943.2020v14n3p267-284}

Moehlecke (2002, p. 198) afirma que "o termo ação afirmativa chega ao Brasil carregado de uma diversidade de sentidos, o que em grande parte reflete os debates e experiências históricas dos países em que foram desenvolvidas". A autora lembra que a redemocratização do Brasil estimulou ainda mais os movimentos sociais que passaram a exigir uma postura mais austera por parte do Poder Público em relação às questões de preconceito contra raça, gênero e etnia. Ao ampliar o leque de direito, o Estado assegura um maior alcance e viabilidade das políticas afirmativas (BRAGA, 2015).

O ano de 1984 é marcado pelos movimentos populares que denunciavam as práticas discriminatórias racistas. Por essa razão, a Constituição de 1988 instaura uma ampliação de direitos, impulsionando um processo nacional respaldado em normatizações que visem coibir quaisquer práticas de racismo, no intuito de promover a igualdade e a tolerância nas diferentes esferas nacionais. Assim, as ações afirmativas têm um papel importante na mudança de postura em relação ao preconceito nas suas mais variadas formas. Por meio delas, o Estado cria programas que visem à melhoria da qualidade de vida e ao atendimento às necessidades essenciais. Em função disso, há mudanças percebidas na representatividade do negro na mídia.

Até os anos 90, eram poucas as ocasiões de representação dos negros nos meios de comunicação e, além disso, ele não figurava como consumidor potencial, ou seja, não era considerado como participante de mercado (LIMA, 1991). Mesmo 51\% da população se autodeclarando negra ou parda, de acordo com o site SAE - Secretaria de Assuntos Estratégicos da Presidência da República do Brasil (2016), os meios de comunicação - em especial a publicidade -, raramente, representavam essa etnia em seus anúncios.

Silva (2005) afirma que houve um aumento na representação negra em jornais e na publicidade em revistas no fim do século XX. No entanto, o estereótipo do negro que emerge nos meios midiáticos de então estava associado à imagem de criminalidade, samba, futebol e papéis menos valorizados. Para desconstruir os ecos dos sentidos sobre o negro na mídia comercial, foi preciso quebrar muitos paradigmas cristalizados ao longo da história da formação da sociedade humana.

As aparições do negro na publicidade como consumidor potencial, datadas no início deste século, fazem referência a um comercial de cerveja. É o primeiro ponto de inserção da representatividade negra, mas ainda conserva uma memória discursiva inscrita em práticas sociais que evidenciam a imagem do negro ao consumo de álcool e que, ainda, o deixam à margem. Para Braga (2015, p. 106), "Cabelo e tom de pele seriam sempre atributos a serem observados e hierarquizados numa gradação onde o objetivo final seria o padrão branco". 


\section{Linguagens - Revista de Letras, Artes e Comunicação - ISSN 1981- 9943 \\ Blumenau, v. 14, n. 3, p. 267-285, set./dez. 2020. \\ DOI: http://dx.doi.org/10.7867/1981-9943.2020v14n3p267-284}

Vale lembrar que o que circula na mídia também circula na sociedade, ou seja, há uma espécie de relação de conivência entre os sentidos partilhados em sociedade e aqueles que se produzem na mídia. De acordo com as reflexões de Foucault ([1971] 2007), há uma ordem que regula o que pode e deve ser dito, o que nos leva a compreender que os discursos que perpetuam o imaginário do negro como um sujeito sem valor circulam porque ainda podem ser ditos.

Os negros formam um importante segmento de mercado, segundo Duarte, Mello e Vannuchi (2004, p. 60). Como "formadores de uma classe média crescente, mas significativa, os negros conseguiram reverter o ostracismo a que são condenados pelo mercado". Vistos como um novo segmento de mercado, o negro passa a ser reconhecido como público com potencial de compra, e os interesses comerciais fazem com que se tenha outro sentido nas relações, (re)criadas em um outro momento histórico, que permite outros dizeres do campo publicitário para o negro.

Logo, além de políticas afirmativas que buscam alçar o negro a posições mais igualitárias no seio social dominado pelo branco como padrão, a publicidade o incluiu em suas peças por reconhecê-lo como consumidor potencial. Mas, o que se percebe, ainda, são resquícios (ou ecos) do que optamos por chamar marcas da senzala que se perpetuam de forma atualizada nas mensagens comerciais. É a memória discursiva que dá preferência ao branco em oposição ao negro.

\section{A PUBLICIDADE COMO ESFERA DE ATIVIDADE}

Segundo Carvalho (1998), a mensagem publicitária pode ser caracterizada como o braço direito na tecnologia moderna. Ela ajuda a criar um modelo de mundo perfeito e ideal. Entretanto, essa mensagem não se restringe ao mundo dos sonhos, uma vez que relaciona o princípio do prazer com o da realidade, pois induz as pessoas a usarem ou comprarem algo. Nem todas as mensagens publicitárias conseguem atingir os efeitos esperados, ainda assim, a publicidade comercial é onipresente na sociedade de consumo.

A publicidade começou a se destacar e a ser reconhecida como prática profissional no Brasil no final do século XIX. A primeira forma publicitária de que se tem registro nasceu de uma colagem do Jornal Gazeta do Rio de Janeiro, que apresentava textos com anúncios e ofertas. Até 1908, a publicidade era apenas de boca a boca e, a partir de então, passa a ser escrita. Os primeiros modelos de agências publicitárias chegaram ao Brasil em 1914, junto com grandes marcas estrangeiras. Esses modelos colaboraram para o aprimoramento da publicidade no âmbito nacional (MARCONDES, 2002). 


\section{Linguagens - Revista de Letras, Artes e Comunicação - ISSN 1981- 9943 \\ Blumenau, v. 14, n. 3, p. 267-285, set./dez. 2020. \\ DOI: http://dx.doi.org/10.7867/1981-9943.2020v14n3p267-284}

Diversos são os meios midiáticos usados pela publicidade para veicular as mensagens, como jornais, televisão, rádio, internet, outdoor, dentre outros. Neste artigo, ainda que por amostragem, buscamos certa diversidade de mídias de publicidade, observando, especificamente, um tempo curto na história, em que aparece a imagem do negro.

Para divulgar e vender produtos e serviços, a publicidade engendra estereótipos que criam uma nova forma de identificação dos produtos em relação aos consumidores. Segundo Baccega (1998), o poder dos paradigmas e demais condicionamentos sociais determina estereótipos epistemológicos, de forma a limitar o fazer científico e interferir no processo de conhecimento do sujeito/pesquisador. Ao distinguir o conceito e o estereótipo, ele ressalta que ambos têm como características uma visão generalizadora da realidade, a qual é transportada pelo signo linguístico.

A publicidade se firma como uma prática característica da sociedade moderna. A busca pela especificidade, a segmentação, tem influenciado cada vez mais na criação de estereótipos. Assim, a publicidade utiliza-se tanto de estereótipos positivos quanto negativos. No caso deste artigo, a análise gira em torno dos estereótipos negativos inerentes à presença do negro na publicidade, na maioria das vezes, em situações desfavoráveis, papéis inferiores e sem posições de destaque.

Pereira e Gomes (2001) descrevem como os meios de comunicação reforçam os estereótipos dos negros, conforme interesses dos grupos dominantes, ditados pelo senso comum conservador de padrão branco. Dessa forma, os negros citados em piadas e frases feitas surgem em jornais, revistas e na televisão para reafirmar os estigmas de negro fora da lei, da mulata sensual ou do atleta bem-sucedido.

As discussões em relação à cor e absorção dos indivíduos pela sociedade, em especial no que diz respeito ao mercado de trabalho, ainda ecoam sentidos consolidados no bojo do sistema escravocrata. Embora haja um imaginário social de desejo de união entre todos os povos, prevalecem sentidos de "superioridade" de uns poucos e da "inferioridade" de muitos o que continua a explicar o valor de mercado da cor (FONSECA, 2001). Esse discurso de poder inerente às raças emerge de práticas discursivas cotidianas na sociedade.

Como fundamentam Pereira e Gomes (2001), a mídia impressa tornou-se um espaço de ambivalência para a representação dos negros, não como agentes sociais, mas apresentados como um recorte estigmatizado. Essa situação resulta do processo histórico-social brasileiro que é composto por esquemas de exclusão dos grupos menos favorecidos, dos quais o negro faz parte. 


\section{Linguagens - Revista de Letras, Artes e Comunicação - ISSN 1981- 9943 \\ Blumenau, v. 14, n. 3, p. 267-285, set./dez. 2020. \\ DOI: http://dx.doi.org/10.7867/1981-9943.2020v14n3p267-284}

Para descrever as características e reflexos do campo discursivo na publicidade, é necessário retomar algumas questões sobre o discurso em articulação com o campo da comunicação. Charaudeau (2015) esclarece que o discurso é fabricado pela língua, mas não é a língua em si. Esta é voltada para a própria organização em sistemas estabelecidos pelas relações entre as formas, combinações e o sentido. Para o autor, descrever a língua é o mesmo que descrever regras de conformidade. O discurso está relacionado a algo além das regras de uso da língua. É resultado da combinação do que se fala ou escreve com a maneira usada para se falar algo.

Para se chegar ao discurso no campo publicitário, é preciso entender como se estabelece o discurso da comunicação. O campo da comunicação é bastante complexo e, nele, convergem vários discursos sociais, além de propiciar outros discursos, os quais são amplificados pela tecnologia, ocupam espaços e promovem silêncios.

Para Pereira e Gomes (2001), as negociações que envolvem os sentidos das mensagens são complexas e têm como consequência imediata a possibilidade de transformar o processo de elaboração discursiva num processo de fabricação da realidade. Nesse sentido, a mídia desempenha papel decisivo quando se fala em discursos de exclusão, pois, ao mesmo tempo em que reproduz ou critica esses discursos excludentes, também aquece os conflitos e expectativas de solucioná-los.

Charaudeau (2015) afirma que a manipulação das mídias também acontece com a publicidade, resultado de um discurso destinado a um público específico. O autor ressalta que a ação manipuladora das mídias é limitada, uma vez que essa manipulação não é totalmente intencional, é exercida mais por efeitos indiretos.

As reflexões e abordagens apresentadas até aqui são a base das análises a seguir, cuja seleção buscou trazer, ainda que metodologicamente amostras, materialidades de mídia impressa e digital, que compreendem o espaço temporal de 1995 a 2016.

\section{O NEGRO NA PUBLICIDADE BRASILEIRA}

O primeiro anúncio a que nos propomos analisar foi veiculado na Revista Veja, de 5 de julho de 1995, edição 1399, ano 28, n 27, p. 20, e traz o pneu da linha Goodyear como carrochefe da empresa DPaschoal, especializada em manutenção de veículos.

Figura 1. Peça publicitária da marca DPaschoal 


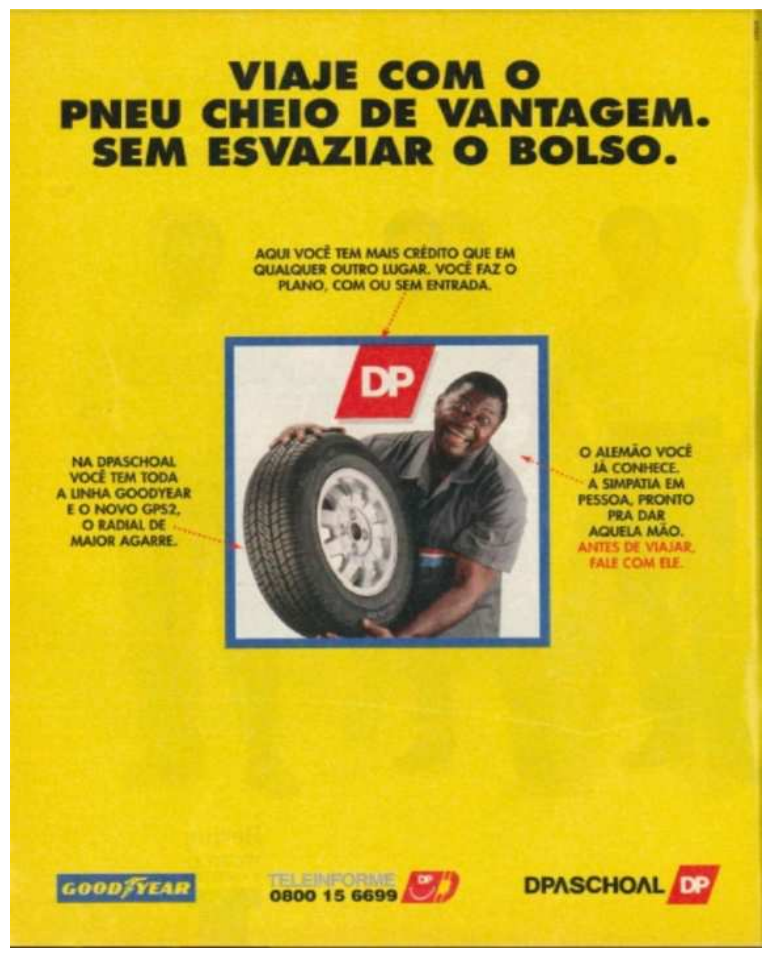

Fonte: Veja (1995, p. 20)

O anúncio da Figura 1 permite várias possibilidades de análise, desse modo, esclarecemos que não buscamos, aqui, esgotar as possibilidades de compreensão dos sentidos, mas sim observar um dos modos de funcionamento discursivo que promove certos efeitos de sentido. Partindo do elemento textual, é possível verificar que os textos foram construídos e direcionados para três pontos específicos da imagem, sendo:

"Aqui você tem mais crédito que em qualquer outro lugar. Você faz o plano, com ou sem entrada". Neste texto, a seta em vermelho está direcionada para o logo da empresa, reforçando a importância da marca: DPaschoal é o centro da propaganda e merece crédito.

"Na DPaschoal você tem toda a linha Goodyear e o novo GPS2, o radial de maior agarre". Agora, a seta aponta para o pneu, enfatizando o valor dos produtos oferecidos pela empresa.

“O Alemão você já conhece. A simpatia em pessoa, pronto para dar aquela mão. Antes de viajar, fale com ele". O elemento verbal aqui destacado faz referência à figura do profissional da empresa, em foco na imagem, ressaltando seu potencial de simpatia e solicitude. É ressaltada a força física do profissional. Esse atributo físico cristaliza-se como uma marca do negro escravo, que era valorizado pelo seu senhor de acordo com sua capacidade motriz. Historicamente, e de acordo com Lopes (1988), embora os negros tivessem adquirido sua 


\section{Linguagens - Revista de Letras, Artes e Comunicação - ISSN 1981- 9943 \\ Blumenau, v. 14, n. 3, p. 267-285, set./dez. 2020. \\ DOI: http://dx.doi.org/10.7867/1981-9943.2020v14n3p267-284}

liberdade após o período escravocrata, eles foram incorporados a estratos inferiores na sociedade, nos quais predominava o trabalho servil.

Na esteira das reflexões de Courtine (2013), é possível observar que essa formulação, em convergência com a imagem do "garoto-propaganda" Alemão, constrói um espaço de interpretação no qual os sinais oferecidos pelo corpo, no caso, a força física, representam sinais de sua identidade psicológica, ou seja, a aptidão para o trabalho pesado e servil inscreve o sujeito na sociedade.

Como aporte teórico dessa possibilidade de interpretação da publicidade, recorremos a Braga (2015), quando afirma que os discursos relacionados aos escravos trazem à tona a qualidade dos atributos servis e do desvelo que o escravo tinha para com o seu senhor. Esse mesmo esmero é perceptível na imagem, na qual a figura de um negro se põe a serviço, não medindo esforços para atender aos clientes da empresa. O gestual do personagem reforça essa característica servil, expondo sua capacidade física e sua disponibilidade para "dar aquela mão".

De acordo com Courtine (2013), o corpo oferece indícios que permitem caracterizar a personalidade do sujeito, por meio da correlação com discursos que retratam questões subjetivas e ideológicas. Assim, ao analisar a formulação "dar aquela mão", observamos que, dada a mão como um membro do corpo, é possível recuperar uma memória discursiva na articulação com um já-dito, quando a mão negra existia com o único propósito de servir a seus senhores. Por outro lado, a expressão facial parece inverossímil, uma vez que apresenta um sorriso forjado e olhos arregalados, abrindo uma brecha sobre a legitimidade da alegria que a imagem tenta transmitir.

Na visão foucaultiana, "o corpo é a superfície sobre a qual o poder atua” (CRUZ, 2007, p. 137). Essa compreensão nos permite afirmar que é sobre os atributos do corpo negro que se estabelece uma relação de poder que preconiza sua inferioridade frente ao homem branco. Esse aspecto inferior é ratificado por meio da associação do negro com as tarefas mais simples. Ora, se observarmos que, historicamente, a abolição não exterminou o trabalho escravo e o negro seguiu desempenhando funções que requeriam forçosamente sua força motriz, a figura do negro como protagonista do anúncio (re)atualiza de modo bastante forte a memória discursiva do sujeito negro (unicamente) como trabalhador braçal.

Outro aspecto que reforça a desigualdade entre brancos e negros é a utilização de um apelido adjetivador: Alemão, em lugar de um nome próprio. Não desconsideramos o efeito humorístico da expressão, já que compreendemos que o substantivo "Alemão" remete a uma população específica, que habita a Alemanha, país europeu que tem sua população majoritariamente branca. No Brasil, o termo "alemão", socialmente, é utilizado para designar 


\section{Linguagens - Revista de Letras, Artes e Comunicação - ISSN 1981- 9943 \\ Blumenau, v. 14, n. 3, p. 267-285, set./dez. 2020. \\ DOI: http://dx.doi.org/10.7867/1981-9943.2020v14n3p267-284}

pessoas excessivamente brancas, recuperando, assim a memória do termo. Seu uso na peça publicitária para referenciar um homem negro remete a efeitos de sentido da ordem do humor, uma vez que, "alemão" carrega consigo uma memória específica e o corpo dado a ver na imagem é negro. Ainda assim, pode-se observar que o uso do apelido reforça a cor negra na medida em que a apaga na nominalização - recuperando uma memória de que o objeto do humor também é o corpo negro.

A próxima peça analisada refere-se à campanha "O dia da mulher brasileira", da marca Riachuelo, e circulou na internet, no canal do YouTube, no dia 6 de março de 2014. Horas após a marca fazer a divulgação do vídeo publicitário, ele foi removido devido à grande repercussão negativa por parte dos próprios consumidores a quem se destinava a propaganda. Esse é um primeiro indício dos efeitos de sentido que fazem funcionar uma memória discursiva sobre a imagem do negro na sociedade: o próprio público alvo da marca se reconhece ofendido. Para este texto, recortamos um frame que consideramos suficientemente simbólico para resumir a perspectiva de todo o anúncio: a peça traz o corpo da modelo branca e só aparecem as mãos negras vestindo-a e lhe adornando com acessórios. Aos leitores que desejem ver a integralidade do vídeo, recomendamos sua busca na plataforma YouTube, facilmente encontrado em diversos canais, apesar de ter sido retirado do canal da marca Riachuelo.

Figura 2. Peça publicitária da marca Riachuelo

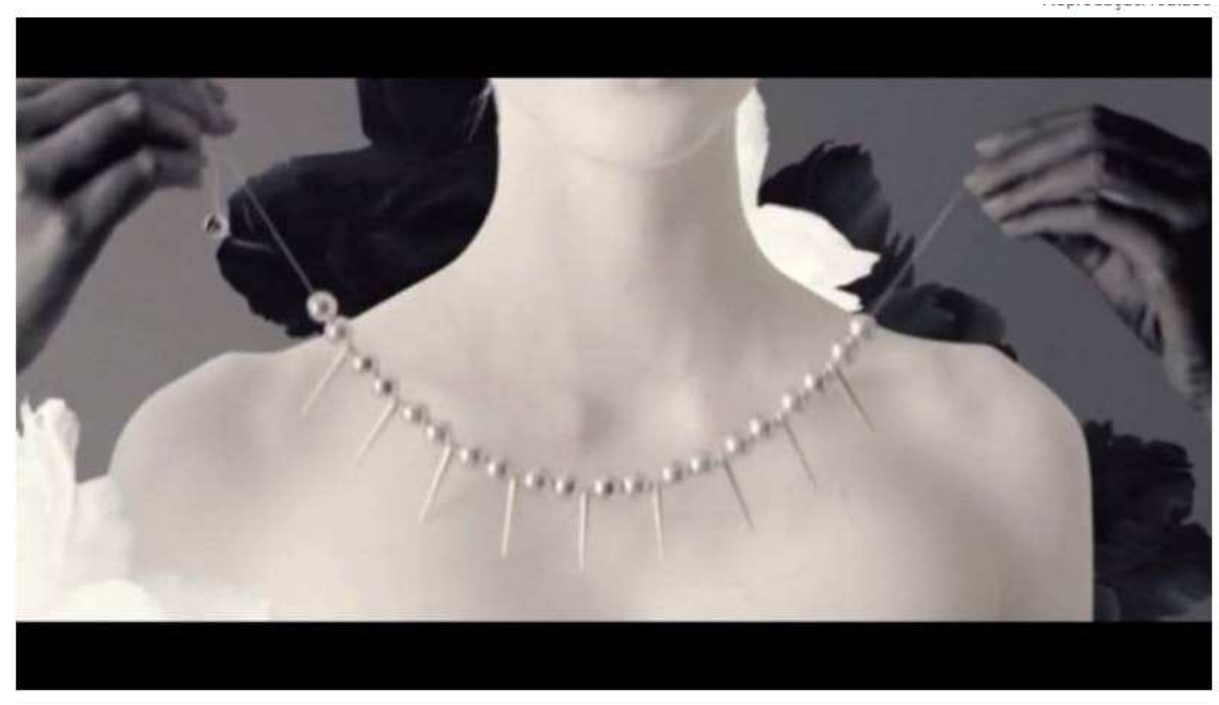

Fonte: YouTube (2014)

A peça publicitária acima foi criada para divulgar a campanha para o Dia Internacional da Mulher. No vídeo, mãos negras servem uma mulher branca, colocando joias e acessórios vendidos pela marca, tal qual podemos observar na Figura 2. O filme de 30 segundos, intitulado 


\section{Linguagens - Revista de Letras, Artes e Comunicação - ISSN 1981- 9943 \\ Blumenau, v. 14, n. 3, p. 267-285, set./dez. 2020. \\ DOI: http://dx.doi.org/10.7867/1981-9943.2020v14n3p267-284}

"O dia da mulher brasileira", inicia-se anunciando que "a Riachuelo preparou uma surpresa para a mulher mais linda do mundo". Desde o início, seja pelo discurso verbal, seja pelo discurso imagético, os efeitos de sentido promovidos sobre a "mulher brasileira Riachuelo", recuperam a memória discursiva da nação construída sobre a padronização do branco europeu na própria formulação da imagem: uma mulher branca, de cabelos claros e lisos, olhos claros, silhueta esbelta. Desse modo, a marca associa padrão de beleza a um tipo específico de corpo, produzindo o apagamento de todos os outros - apagamento que ocorre, inclusive, imageticamente, uma vez que a representação do corpo negro da mulher é formulada, unicamente, por suas mãos. Estas, ainda, em ritual de subserviência, trazem produtos da marca para serem ofertados ao corpo alvo que se dá a ver no vídeo. Já o corpo branco aparece representado também por um rosto - produtor de identificação do indivíduo e, segundo Courtine (2013, p. 7), "O rosto seduz com maior segurança, mais subtilmente ainda do que as palavras". Assim, enquanto o corpo negro é retratado apenas por sua parte servil - as mãos, como também ocorre na peça publicitária da marca D'Paschoal -, o corpo branco tem um rosto para assegurar a adesão do público alvo.

A essa imagem, logo se somam mãos negras e plumas negras, realçando ainda mais a alvura da mulher branca. Torna-se relevante observar que, apenas as mãos negras aparecem e fazem alusão à mulher negra, promovendo efeitos de sentido calcados num discurso de subserviência fortemente construído historicamente e ecoando na atualidade a escravidão colonial, em que a mulher negra servia à sua sinhá.

A ausência do corpo feminino negro na peça publicitária apaga e exclui do campo de sentidos "a mulher mais linda do mundo" e "a mulher brasileira" a própria mulher negra, negando a ela a identificação como consumidora da marca, num batimento direto com a memória de uma nação pós-escravocrata que conferiu à mulher negra postos de trabalho subalternos. Em consonância com as reflexões de Fonseca-Silva (2007, p. 29), “o domínio de memória indica que esses anúncios, como lugares de memória discursiva, refletem representações sociais sobre aquilo que a sociedade aprendeu a pensar sobre a mulher".

A partir dessa reflexão, constroem-se sentidos e são dados a ver indícios do que denominamos marcas da senzala que ainda circulam na publicidade contemporânea. Ora, se existe esse tipo de circulação de sentidos é porque ainda permanecem discursos (e práticas!) racistas atualmente. "A contemporaneidade, as relações de poder, criam necessidades, desejos, na medida em que criam, paralelamente, soluções a serem consumidas" (BRAGA, 2015, p. 234). 


\section{Linguagens - Revista de Letras, Artes e Comunicação - ISSN 1981- 9943 \\ Blumenau, v. 14, n. 3, p. 267-285, set./dez. 2020. \\ DOI: http://dx.doi.org/10.7867/1981-9943.2020v14n3p267-284}

A última peça analisada é a propaganda do Leite Italac, que foi veiculada na Revista Veja, edição 2495, de 14 de setembro de 2016, disponível nas páginas 28 e 29.

Figura 3. Peça publicitária da marca Italac
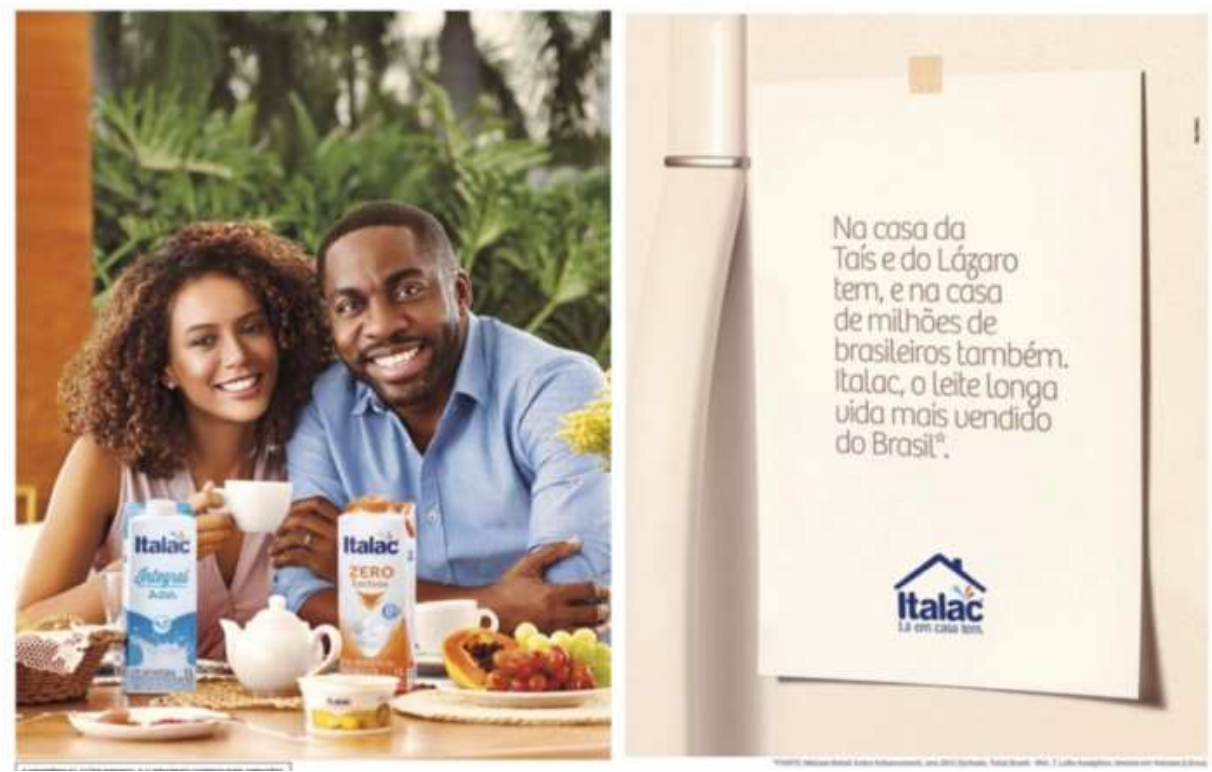

Fonte: Veja (2016, p. 28-29)

O enunciado é formado pela linguagem verbal que diz: "Na casa da Taís e do Lázaro tem, e na casa de milhões de brasileiros também. Italac, o leite longa vida mais vendido do Brasil". O elemento imagético atualiza uma memória a partir da compreensão de que a família negra representa milhões de brasileiros. Nesse sentido, fica ratificado o valor que representam para a sociedade brasileira.

Entretanto, é preciso considerar que se trata de uma família de artistas e, no momento em que a publicidade foi veiculada, o casal estava em evidência, protagonizando uma minissérie na televisão. Vale ressaltar que os negros "famosos" são, comumente, "valorizados", como os artistas e os jogadores de futebol que se destacam. Taís Araújo e Lázaro Ramos são exemplos de artistas negros valorizados pela mídia e que, na atualidade, despontam em comerciais na TV e publicidades em geral.

Nessa peça, é possível perceber a existência de outro discurso: o negro tem a representatividade do brasileiro. Tomada como enunciado sincrético, promove sentidos aliados a uma reafirmação do seu valor como cidadão, embora o corpo negro "famoso" trazido para a imagem não seja representativo do corpo negro "real", da vida cotidiana.

Voltando à linguagem imagética, é notória a valorização das raízes negras por parte da atriz que usa o cabelo crespo, que não remete a um possível "embranquecimento", pois enaltece 


\section{Linguagens - Revista de Letras, Artes e Comunicação - ISSN 1981- 9943 \\ Blumenau, v. 14, n. 3, p. 267-285, set./dez. 2020. \\ DOI: http://dx.doi.org/10.7867/1981-9943.2020v14n3p267-284}

a beleza do cabelo crespo da mulher negra, em contraposição ao discurso racista de moda vigente desde os anos 1990 que adotou o cabelo liso como símbolo de beleza, marginalizando o crespo como sendo "cabelo ruim". A linguagem encerra a mensagem: "Italac, lá em casa tem", acionando uma memória que se inscreve na esfera da intimidade e, portanto, da representatividade de que em todo lar tem leite, sobretudo, no lar do negro.

Após analisar o material que compõe este artigo, é possível observar uma certa mutação do discurso ao longo das últimas décadas, mas que não se esgotou em si, porque dentre as três peças analisadas, que aqui servem metonimicamente como representação da publicidade no Brasil, duas produzem sentidos que remetem à servidão a qual o negro foi submetido historicamente no país, demonstrando que essa mudança se encontra em penoso processo de construção, em que formações discursivas distintas em relação ao espaço do corpo negro se embatem todos os dias, engendrando discursos racistas e discursos de luta e resistência.

Vale lembrar que as mudanças já alcançadas foram impulsionadas pelas ações afirmativas e pelo discurso de resistência de pessoas que, inconformadas com os indícios que permitem fazer circular o racismo presente na publicidade, se fizeram ouvir, conseguindo, inclusive, a retratação por parte da empresa que retirou o vídeo da Riachuelo do ar.

As marcas da senzala que buscamos trazer à tona faziam parte da estratégia enunciativa das peças publicitárias da maneira como Foucault ([1969] 2014) afirma de forma "não visível", mas, principalmente, “não oculta”. Mediante as reflexões realizadas, colocamo-nos na esteira dos postulados de Braga (2015, p. 242), "os padrões desfazem-se em diversos outros, que nascem de outros discursos, que carregam novos sentidos, que constroem novas identidades. [...] o "reconhecimento" do negro, hoje, ultrapassa a esfera do corpo".

\section{CONSIDERAÇÕES FINAIS}

Durante anos, o continente africano teve como principal função abastecer o mercado de trabalho ocidental com mão de obra escrava. Os discursos construídos e veiculados, desde então, sobre os negros sempre foram de massacre, animalização, abjeção, inferioridade, opressão, cujos efeitos de sentido criaram, desde aquela época, uma imagem muito inferior e distorcida dos sujeitos negros.

Não foram apenas as ações que destruíram o físico e o psicológico dos negros, mas os discursos e agressões da linguagem constantemente proferidas. Hoje, nota-se que as correntes da senzala começam a ser rompidas, pelo menos no campo publicitário. Fato esse que pode ser confirmado por meio das reflexões de alguns exemplos de peças publicitárias estudadas. 


\section{Linguagens - Revista de Letras, Artes e Comunicação - ISSN 1981- 9943 \\ Blumenau, v. 14, n. 3, p. 267-285, set./dez. 2020. \\ DOI: http://dx.doi.org/10.7867/1981-9943.2020v14n3p267-284}

Como evidenciado ao longo da análise, ainda existem discursos que reatualizam uma memória do papel do negro escravo, associando sua imagem com atividades braçais, depreciando suas características físicas, estabelecendo seu papel de inferioridade dentro das relações de poder.

Ao analisar as peças publicitárias, observa-se uma movência nos enquadramentos dados à imagem do negro ao longo do período analisado. A primeira publicidade analisada, publicada em 1995, demonstra uma construção da imagem de negro de forma servil e solícita, que traz à tona seu passado de servidão. A segunda peça, datada de 2014, possui indícios que demonstram uma mudança de atitude por parte da sociedade que, motivada pelas políticas afirmativas, não aceitam passivamente a discriminação velada em anúncios publicitários. Isso se confirma pela mobilização social que resultou na suspensão do vídeo da Riachuelo, considerado racista pelos internautas. Por fim, a última peça, datada de 2016, demonstra uma mudança de percepção, assegurando ao negro uma maior representatividade na mídia. Vale ressaltar que esses são apenas alguns exemplos, outras regularidades foram observadas em um trabalho de maior amplitude e ajudam a comprovar o que foi constatado por meio das análises apresentadas.

Com relação ao reflexo das políticas afirmativas na publicidade brasileira contemporânea, é possível afirmar que houve uma mudança na construção dos discursos em relação ao negro, o qual começa a conquistar, paulatinamente, sua representatividade na publicidade contemporânea brasileira. A partir da proliferação dos movimentos sociais e da configuração das políticas afirmativas incorporadas pelo Estado, os negros ganharam mais visibilidade e se confirmaram no cenário publicitário como um público em potencial e, com isso, reforçam a própria identidade.

Em síntese, é possível observar que, discursivamente, o corpo negro sempre ocupou um lugar em peças publicitárias. Trazendo em seu interdiscurso o signo da escravidão, que marcou a identidade negra como subserviente a outra raça, as peças publicitárias brasileiras, ainda na atualidade, como mostra a propaganda da Riachuelo, recuperam, em alguma medida, essa imagem do negro, remontando uma memória fiada no discurso racista desde o Brasil Colônia. É evidente, como sabemos, que pouco importa a intencionalidade e, por isso, a retratação da empresa; o que interessa aos analistas do discurso é da ordem do discurso e dos seus efeitos de sentido. Sendo assim, na materialidade, observamos ainda o discurso racista sendo constituído a partir dos mesmos signos de sempre. Em contrapartida, em um jogo discursivo que engendra uma formação discursiva lateral, as ações afirmativas surgem para incluir na ordem do discurso e na ordem do olhar, outros sentidos ao corpo negro - afinal, a aparição do corpo negro já ocorria na publicidade, o que faltava era lhe atribuir sentidos que não fossem associados à 


\section{Linguagens - Revista de Letras, Artes e Comunicação - ISSN 1981- 9943 \\ Blumenau, v. 14, n. 3, p. 267-285, set./dez. 2020. \\ DOI: http://dx.doi.org/10.7867/1981-9943.2020v14n3p267-284}

senzala. A partir da peça publicitária da Italac, vemos essa tentativa, ainda desajeitada, de incluir o corpo negro como representante de uma parcela da população, promovendo sentidos da ordem da identificação por meio da cor da pele. No entanto, o "desajeitada" ainda se deve a essa representação estar associada a um casal rico e famoso, deixando à deriva o corpo negro brasileiro do cotidiano, aquele que ainda vive na marginalidade, se esgueirando entre as trincheiras de discursos ora racistas, ora de inclusão.

\section{REFERÊNCIAS}

ABRAHÃO, B., SOARES, A. O corpo negro e os preconceitos impregnados na cultura: uma análise dos estereótipos raciais presentes na sociedade brasileira a partir do futebol.

Movimento, n. 17, vol. 04, 2011. Disponível em:

https://seer.ufrgs.br/index.php/Movimento/article/view/20590/15210. Acesso em 21 jan 2019.

ALMEIDA, Isaac D'Leon. Marcas da senzala na construção da imagem do negro na publicidade brasileira contemporânea. 2016. 113 f. Dissertação (Mestrado em Linguística) - Universidade de Franca. Franca, 2016.

BACCEGA, M. A. Comunicação e linguagem: discursos e ciência. São Paulo: Moderna, 1998.

BRAGA, A. B. História da beleza negra no Brasil: discursos, corpos e práticas. São Carlos: EdUFSCar, 2015.

CARVAlHO, N. Publicidade: a linguagem da sedução. São Paulo: Palas Athena, 1998.

CHARAUDEAU, P. Discurso das mídias. São Paulo: Contexto, 2015.

COURTINE, J. Decifrar o corpo: pensar com Foucault. Petrópolis: Vozes, 2013.

COURTINE, J. Análise do discurso político: o discurso comunista endereçado aos cristãos. São Carlos: EdUFSCar, 2009.

CRUZ, M. S. A cultura popular nas malhas do discurso: a mecânica do poder em espaços turísticos. In: FONSECA-SILVA, M. C.; POSSENTI, S. (Org.) Mídia e rede de memória. Vitória da Conquista: Uesb, 2007. p. 77-91.

DUARTE, S., MELO, L., VANNUCHI, C. Cheios de raça. Isto É, n. 1789. São Paulo: Três, 2004.

FONSECA, M. N. S. Retratos em branco e preto: o negro no imaginário cultural brasileiro. In: PEREIRA, E. A.; GOMES, N. P. (Org.) Ardis da imagem: exclusão étnica e violência nos discursos da cultura brasileira. Belo Horizonte: Mazza \& PUCMinas, 2001. p. 15-26.

FONSECA-SILVA, M. C. Mídia e lugares de memória discursiva. In: FONSECA-SILVA, M. C.; POSSENTI, S. (Org.) Mídia e rede de memória. Vitória da Conquista: Uesb, 2007. p. 11-37. 
FOUCAULT, M. O sujeito e o poder. In: RABINOW, P.; DREYFUS, H. (Org.). Michel Foucault: uma trajetória filosófica. Rio de Janeiro: Forense, 1995.

FOUCAULT, M. [1971] A ordem do discurso. São Paulo: Loyola, 2007.

FOUCAULT, M. [1969] A arqueologia do saber. Rio de Janeiro: Forense Universitária, 2014.

FERNANDES, C. A. Discurso e sujeito em Michel Foucault. São Paulo: Intermeios, 2012.

GREGOLIN, M. R. V. Discurso e a produção de identidades na mídia. In: FONSECASILVA, M. C.; POSSENTI, S. (Org.). Mídia e Rede de Memória. Vitória da Conquista: Uesb, 2007.

LIMA, L. A. N. Capoeira Angola: lição de vida na civilização brasileira. 1991. 142 f. Dissertação (Mestrado em Psicologia) - Faculdade de Psicologia, Pontifícia Universidade Católica de São Paulo, 1991.

LOPES, J. M. S. C. Preto no branco: em busca das raízes do preconceito contra o negro no Brasil. Belo Horizonte: Colégio Marista Dom Silvério, 1988.

MARCONDES, P. Uma história da propaganda brasileira: as melhores campanhas, gênios da criação, personagens. Rio de Janeiro: Ediouro, 2002.

MOEHLECKE, S. Ação afirmativa: história e debates no Brasil. Cadernos de Pesquisa, $\mathrm{n}$. 117, vol. 2, 2002. Disponível em: http://www.scielo.br/pdf/cp/n117/15559.pdf. Acesso em: 12 dez. 2018.

PEREIRA, E. A.; GOMES, N. P. M. Ardis da imagem: exclusão étnica e violência nos discursos da cultura brasileira. Belo Horizonte: Mazza \& PUC Minas, 2001.

SAE. Banco de dados mostra situação da população negra do Brasil. Site. 2016.

Disponível em: http://www.sae.gov.br/imprensa/noticia/materias/banco-de-dados-mostrasituacao-da-populacao-negra-do-brasil/. Acesso em: 01 jan 2019.

SCHWARCZ, L. M. Nem preto, nem branco, muito pelo contrário: cor e raça na sociabilidade brasileira. São Paulo: Claro Enigma, 2012.

SILVA, P. V. B. Racismo discursivo na mídia: pesquisa brasileira e movimentação social. Anais da 28 ${ }^{a}$ Reunião Anual da ANPEd. Caxambu: Associação Nacional de Pesquisa e Pósgraduação em educação, 2005. 